\title{
Long-Term Prospective Clinical And Radiographic Outcomes After Minimally Invasive Lateral Transiliac Sacroiliac Joint Fusion Using Triangular Titanium Implants
}

This article was published in the following Dove Press journal:

Medical Devices: Evidence and Research

Peter G Whang,' Emily Darr, ${ }^{2}$ S Craig Meyer, ${ }^{3}$ Don Kovalsky, (D) ${ }^{4}$ Clay Frank, (D) Harry Lockstadt, ${ }^{6}$ Robert Limoni, ${ }^{7}$ Andy J Redmond, ${ }^{8}$ Philip Ploska, ${ }^{9}$ Michael Oh, (1D) ${ }^{10}$ Abhineet Chowdhary," Daniel Cher, (D) ${ }^{12}$ Travis Hillen $^{13}$

'Department of Orthopedics and Rehabilitation, Yale University School of Medicine, New Haven, CT, USA; ${ }^{2}$ Department of Orthopaedics, Medical University of South Carolina, Charleston, SC, USA; ${ }^{3}$ Columbia Orthopaedic Medical Group, Columbia, Mo, USA; ${ }^{4}$ Orthopaedic Center of Southern Illinois, Mt. Vernon, IL, USA; ${ }^{5}$ Integrated Spine Care, Wawautosa, WI, USA; ${ }^{6}$ Bluegrass Orthopedics, Lexington, KY, USA; ${ }^{7}$ BayCare Clinic Orthopedics and Sports Medicine, Green Bay, WI, USA;

${ }^{8}$ Precision Spine Care, Tyler, TX, USA; ${ }^{9}$ OrthoSpine Solutions, Stockbridge, GA, USA; ${ }^{10}$ Department of Neurosurgery, Allegheny General Hospital, Pittsburgh, PA, USA; " Neuroscience Institute, Overlake Hospital, Bellevue, WA, USA; ${ }^{12}$ Clinical Affairs, SI-BONE, Inc, Santa Clara, CA, USA; ${ }^{13}$ Department of Radiology, Division of Diagnostic Radiology, Musculoskeletal Section, Washington University St. Louis, St. Louis, MO, USA

Correspondence: Peter G Whang Department of Orthopaedics and Rehabilitation, Yale University School of Medicine, P.O. Box 20807I, New Haven, CT 06520-807I, USA

Email peter.whang@yale.edu
Background: Accumulating evidence supports the long-term safety and effectiveness of minimally invasive sacroiliac joint fusion (SIJF) for sacroiliac joint dysfunction.

Objective: To report 5-year clinical and radiographic follow-up in patients undergoing SIJF using triangular titanium implants (TTI).

Methods: One hundred and three subjects at 12 centers treated with SIJF using TTI in two prospective clinical trials (NCT01640353 and NCT01681004) were enrolled and followed in the current study (NCT02270203) with clinic visits at 3, 4 and 5 years. CT scans performed at 5 years were compared to prior CT scans (at 1 or 2 years) by an independent radiologist. Results: Compared to baseline scores, SIJ pain scores at 5 years decreased by a mean of 54 points, disability scores (Oswestry Disability Index) decreased by 26 points, and quality of life scores (EuroQOL-5D time trade-off index) increased by 0.29 points $(0-1$ scale) (all $\mathrm{p}<0.0001$ ). Satisfaction rates were high and the proportion of subjects taking opioids decreased from $77 \%$ at baseline to $41 \%$ at 5 -year follow-up. Independent radiographic analysis showed a high rate $(98 \%)$ of bone apposition to implants on both the sacral and iliac sides of the SI joint, with a high rate of bony bridging $(87 \%)$ and a low rate of radiolucencies suggestive of loosening (5\%).

Conclusion: A 5-year follow-up showed continued excellent clinical responses in patients with SIJ pain treated with SIJF using triangular titanium implants along with a high rate $(88 \%)$ of joint fusion.

Level of evidence: Level II.

Keywords: sacroiliac joint pain, sacroiliac joint degeneration, arthrodesis, sacroiliac joint fusion

\section{Introduction}

A $15-30 \%$ of patients with chronic low back pain have pain originating from the sacroiliac joint (SIJ). ${ }^{1-5}$ SIJ pain impairs quality of life similarly to other spine conditions. ${ }^{6,7}$ Non-surgical treatments, such as physical therapy, chiropractic, intraarticular SIJ steroid injections, prolotherapy, and radiofrequency neurotomy of sacral nerve root branches, have minimal evidentiary support. ${ }^{8-13}$ No available high-quality studies support the long-term effectiveness of any non-surgical treatment.

Minimally invasive sacroiliac joint fusion (MIS SIJF) is an increasingly accepted surgical option for SIJ dysfunction. While some available devices and 
allograft products are placed through a dorsal surgical approach, the evidence base supporting the safety and effectiveness of such strategies is minimal. Most commercially available implant systems for MIS SIJF are placed with a lateral transarticular approach, and triangular titanium implant (TTI) remains the most thoroughly studied device. MIS SIJF using this approach has been evaluated and found to be both safe and effective as documented by multiple health technology assessments including BCBSA $^{14}$ and National Institute for Health and Care Excellence (NICE, UK, see IPG 578). ${ }^{15}$

To date, the vast majority of published evidence for lateral transiliac SIJF involves the use of porous triangular titanium implants (TTI, iFuse Implant System, SI-BONE, Inc., Santa Clara, CA, USA). Evidence supporting improvement in pain, disability and quality of life after SIJ fusion with TTI derives from 3 prospective clinical trials, ${ }^{16-18}$ numerous case series ${ }^{19-24}$ and comparative case series. ${ }^{25-27}$ Herein, we report 5-year prospective follow-up from two multicenter clinical trials of TTI for SIJF: INSITE (NCT01681004, a prospective, randomized controlled trial of SIJ fusion vs non-surgical management) ${ }^{16}$ and SIFI (NCT01640353, a prospective multicenter single-arm study). ${ }^{18}$ Both studies enrolled patients with chronic SIJ pain diagnosed via history, physical examination and confirmatory diagnostic SIJ block with a local anesthetic. In the feeder studies, subjects underwent SIJF with TTI in a brief minimally invasive surgery and had structured follow-up visits to 2 years. Published reports showed marked, immediate and sustained improvements in pain, disability and quality of life throughout follow-up. ${ }^{16,18}$ Herein, we report 5-year clinical and radiographic follow-up from the same cohort.

\section{Methods}

\section{Participants}

Subjects included in the current study (LOIS, Long Term Outcomes from INSITE and SIFI, NCT02270203) were enrolled at 12 centers who participated in either INSITE or SIFI (Appendix 1). INSITE is a prospective multicenter randomized trial of SIJF vs non-surgical management whose 2-year results showed considerable improvements in pain, disability and quality of life in the surgical group but only modest responses in the non-surgical group. ${ }^{16}$ SIFI is a prospective multicenter single-arm clinical trial evaluating the same procedure/device with an identical follow-up and assessment schedule; 2-year results were similarly positive. ${ }^{18} \mathrm{~A}$ pooled analysis of these trials (along with a randomized trial from Europe $)^{17}$ confirmed marked homogeneity of study results. ${ }^{28}$ As reported previously, patients enrolling in INSITE and SIFI were diagnosed with SIJ dysfunction due to degenerative sacroiliitis or sacroiliac joint disruption based upon medical history, a positive Fortin Finger test, ${ }^{29}$ at least 3 positive physical examination signs suggestive of SIJ dysfunction, and a positive diagnostic SIJ block performed under fluoroscopic or CT guidance. Key INSITE/SIFI exclusion criteria were severe low back or hip pain due to other conditions, SIJ dysfunction due to autoimmune or inflammatory conditions and osteoporosis (see previously publications ${ }^{16,18}$ for details).

Participating LOIS sites had to have enrolled and treated at least 5 patients with SIJF with sufficient clinical trial resources, including a dedicated study investigator and coordinator who could carry out trial requirements and the ability to maintain meaningful enrollment and followup for this long-term study. Of the 39 sites participating in INSITE and SIFI, 12 sites met study participation criteria. To qualify for LOIS, a subject had to have undergone SIJF with TTI within the INSITE or SIFI studies and sign a LOIS-specific informed consent form. Potential study participants were screened for study eligibility criteria and reasons for non-participation (not meeting criteria or refusal to participate) were captured.

\section{Interventions And Assessments}

LOIS assessments included in-person study visits that took place at years 3, 4 and 5 during which time subjects completed surveys to assess SIJ pain and low back pain scores (a 100-mm visual analog scale [0-100 scale]); disability (Oswestry Disability Index, a validated measure of disability due to back pain; ${ }^{30}$ quality of life (EuroQOL-5D, a commonly used generic quality of life survey that produces a health state utility value ranging from 0 [death; values $<0$ are possible, representing health states worse than death] to 1 [perfect health]); ${ }^{31}$ and satisfaction. All questionnaires were administered by trained study research coordinators. In addition, phone calls to subjects were completed at years 2.5, 3.5 and 4.5; these were intended to maintain subject contact and assess adverse events. Adverse events were assessed during both in-clinic and phone visits using a broad definition from an international clinical trial standard (ISO14155:2011). Study site personnel and study monitors also reviewed medical records to ensure complete adverse event reporting during the study follow-up. For each event, the site investigator was 
required to assess the severity and relatedness of the adverse event to the SIJF or a pre-existing condition; the relatedness to device or procedure was characterized as definitely, probably, possibly, unlikely or not related. The study did not incorporate any structured program to promote opioid cessation.

\section{Radiographic Analysis}

As part of INSITE and SIFI, all LOIS participants had undergone high-resolution ( $<1 \mathrm{~mm}$ slice thickness) CT scans of the pelvis without contrast at either 2 years (INSITE) or 1 year (SIFI). LOIS participants also underwent a similar CT scan at 5 years. All radiographic analysis was performed by an independent musculoskeletal radiologist (author TH). The primary radiographic endpoint was the proportion of subjects undergoing 5-year CT scan who show at least 30\% apposition of bone to both the iliac and sacral sides of at least 2 of 3 iFuse implants at 5 years. Additional radiographic endpoints included the following: radiolucencies consistent with device loosening, bridging bone across the SIJ, assessed as continuous bridging across the treated joint, occurring either adjacent to implants, distant from implants and/or adjacent/ distant from implants, degree of bridging ( $<5 \%$ of joint, $5-15 \%, 15-30 \%$, or $30-100 \%$ ), signs of both positive and/ or adverse bone remodeling, device failure or migration, and heterotopic ossification. Positive bone remodeling was defined as presence of increased bone density adjacent to the implant that appears to be due to new bone formation and an increase in mechanical demand at the bone-implant interface. Adverse bone reaction was defined as presence of new erosions, cysts, signs of infection, osteolysis or other pathologic reactions in the bone adjacent to the implant. Analysis was conducted on a per-side or, in some cases, per-implant basis. Twelve subjects underwent unplanned contralateral SIJ fusion between years 1 and 5, resulting in iFuse or iFuse-3D devices (11 of 12 cases) evident on 5-year CT scans. However, since these implants do not represent 5 -year residence in the body, these treated sides were excluded from the analysis.

\section{Study Ethics}

All centers obtained study-specific institutional review board (IRB) approval prior to study initiation. Subjects were paid nominal amounts for their time and expenses required to complete study visits and call requirements, as approved by each site's governing IRB. The study was sponsored by the device manufacturer (SI-BONE, Inc., Santa Clara, CA).

\section{Data Collection And Monitoring}

All study data were entered into an electronic data capture system. All study sites underwent remote and regularly scheduled on-site data monitoring visits by sponsor representatives so that all collected data could be verified against source documents maintained at the sites.

\section{Endpoints}

The primary efficacy success endpoint for this study is a composite, defined as a reduction from pre-operative VAS SIJ pain score of at least 20 points in the absence of devicerelated serious adverse event, absence of neurological worsening, and absence of surgical revision. This endpoint is identical to that used in the component trials (INSITE, SIFI) and was assessed at 3, 4 and 5 years in the LOIS trial. Other outcomes include improvements in SIJ pain scores (VAS), disability (Oswestry Disability Index), and quality of life (EuroQOL-5D) across all time points; proportion of non-working subjects who return to work; and occurrence of serious adverse events. The study's primary radiographic endpoint (i.e. the proportion of treated sides with at least $30 \%$ apposition of bone to both the iliac and sacral sides of at least 2 of 3 iFuse devices on 5-year CT scans) was designed to be consistent with literature from other metallic devices showing the adequacy of this level of bone binding for positive patient outcomes. ${ }^{32}$

\section{Statistical Analysis}

A standard approach to statistical analysis was employed to calculate standard aspects of change scores and binary outcomes. Repeated-measures analysis of variance was used to evaluate changes from baseline over time in continuous measures. Where relevant, binary outcomes were evaluated with a chi-squared test, McNemar test, or exact binomial confidence intervals.

\section{Data Availability}

The study sponsor (SI-BONE) will share full, deidentified study data with physicians proposing specific analyses through Yale University's Yale Open Data Access (YODA) program. ${ }^{33}$

\section{Results \\ Participants}

Of 127 potentially eligible INSITE/SIFI subjects, 103 were enrolled in LOIS. Reasons for non-participation included inability to participate due to health issues $(n=2)$, death prior to screening (3), lost to follow-up during 
the previous study (4), moved out of state (1), refused study participation (11), planning pregnancy (1), previous withdrawal from INSITE or SIFI (1), and unlikely to be compliant (1).

\section{Patient Flow}

A 5-year follow-up was available in 93 (90\%) subjects. Reasons for attrition include loss to follow-up $(n=6)$, death due to other causes $(n=2)$, and withdrawal of consent $(n=2$, Figure 1).

\section{Baseline Characteristics}

Subjects (mean age 51 years) were mostly Caucasian $(97 \%)$ and female (73\%, Table 1). Subjects had high preoperative pain scores (mean [SD] of 81.5 [12.7]) and high levels of disability (ODI score 56.3 [12.1]). The duration of pain prior to enrollment averaged 5.7 years. EQ-5D at baseline was $0.45(0.17)$, indicating a very poor quality of life. ${ }^{6}$ A $77 \%$ of subjects were taking opioids for back or SIJ pain preoperatively and $45 \%$ had a history of lumbar fusion, and concomitant spine and hip disease was

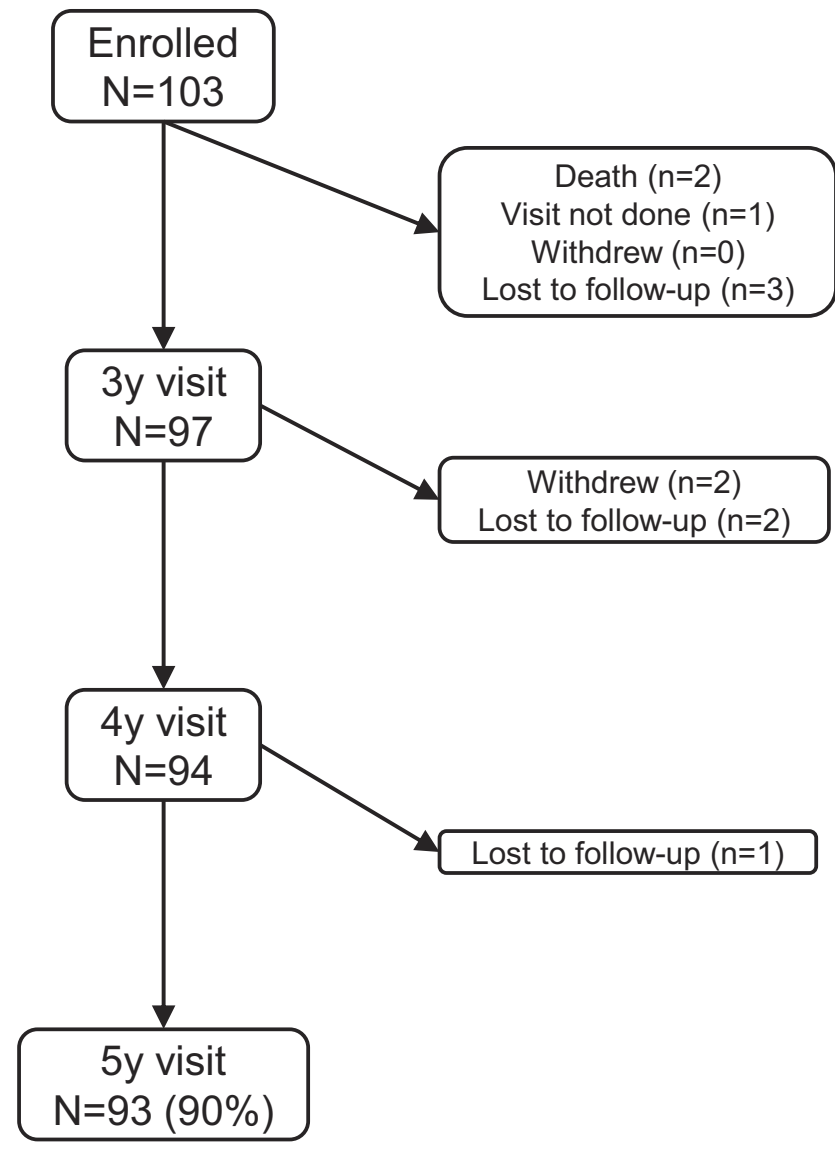

Figure I Patient follow-up in LOIS study.
Table I Baseline And Surgical Characteristics Of Study Participants $(n=103)$

\begin{tabular}{|l|l|}
\hline Baseline characteristics & \\
Age, years, mean (SD) & $50.8(10.8)$ \\
Female, $\mathrm{n}$ (\%) & $75(72.8 \%)$ \\
Body mass index, mean (SD) & $31.0(7.4)$ \\
Non-white race, $\mathrm{n}(\%)$ & $3(2.9 \%)$ \\
Hispanic, $\mathrm{n}$ (\%) & $3(2.9 \%)$ \\
History of prior lumbar fusion & $46(44.7 \%)$ \\
Current smoker, $\mathrm{n}(\%)$ & $19(18.4 \%)$ \\
Pain began in peripartum period, $\mathrm{n}(\%)$ & $14(13.6 \%)$ \\
Pain duration, years, mean (SD) & $5.7(6.8)$ \\
Visual analog scale SIJ pain, mean (SD) & $81.5(12.7)$ \\
Oswestry Disability Index, mean (SD) & $56.3(12.1)$ \\
EuroQOL-5D, TTO index & $0.45(0.17)$ \\
Taking opioids, $\mathrm{n}$ (\%) & $79(76.7 \%)$ \\
\hline Surgical characteristics & \\
Right side, $\mathrm{n}$ (\%) & $42(40.8 \%)$ \\
Bilateral SIJ fusion, $\mathrm{n}$ (\%) & $10(9.7 \%)$ \\
Operative duration (minutes), mean (SD) & $46.3(16.4)$ \\
Hospital length of stay (days), mean (SD) & $0.72(0.93)$ \\
Number of implants, $\mathrm{n}$ (\%) & \\
2 & $2(1.9 \%)$ \\
3 & $80(77.7 \%)$ \\
4 & $21(20.4 \%)$ \\
\hline
\end{tabular}

common. Most (93, 90.3\%) patients underwent unilateral SIJF on either of the treatment studies; 10 (9.7\%) exhibited pain, physical examination signs and appropriate responses to diagnostic blocks consistent with bilateral SIJ dysfunction and therefore underwent bilateral SIJF.

\section{Clinical Outcomes}

At 5 years, the mean SIJ pain score had decreased from 81.5 (SD 12.7) to 27.1 (29.4), a mean change from baseline of 54.1 (32.3) points $(\mathrm{p}<0.0001$, Figure 2). Seventy-seven $(82.8 \%)$ subjects had improvements of at least 20 points in SIJ pain scores. Study success (VAS improvement of at least 20 points in the absence of severe device-related adverse event, neurologic adverse event and revision surgery) was observed in 76 subjects at 60 months (81.7\%, 95\% CI 72.4-89.0\%); one subject underwent early revision for implant malposition but otherwise had marked improvements in pain and disability. Oswestry Disability Index, a measure of disability due to back pain, decreased from 56.3 (12.1) pre-operatively to 29.9 (21.2) at 5 years, an improvement of 26.2 (21.6) points $(p<0.0001)$. Sixty-four $(68.8 \%)$ subjects had an improvement in ODI scores of at least 15 points from their preoperative score. EuroQOL-5D time trade-off index score, a 

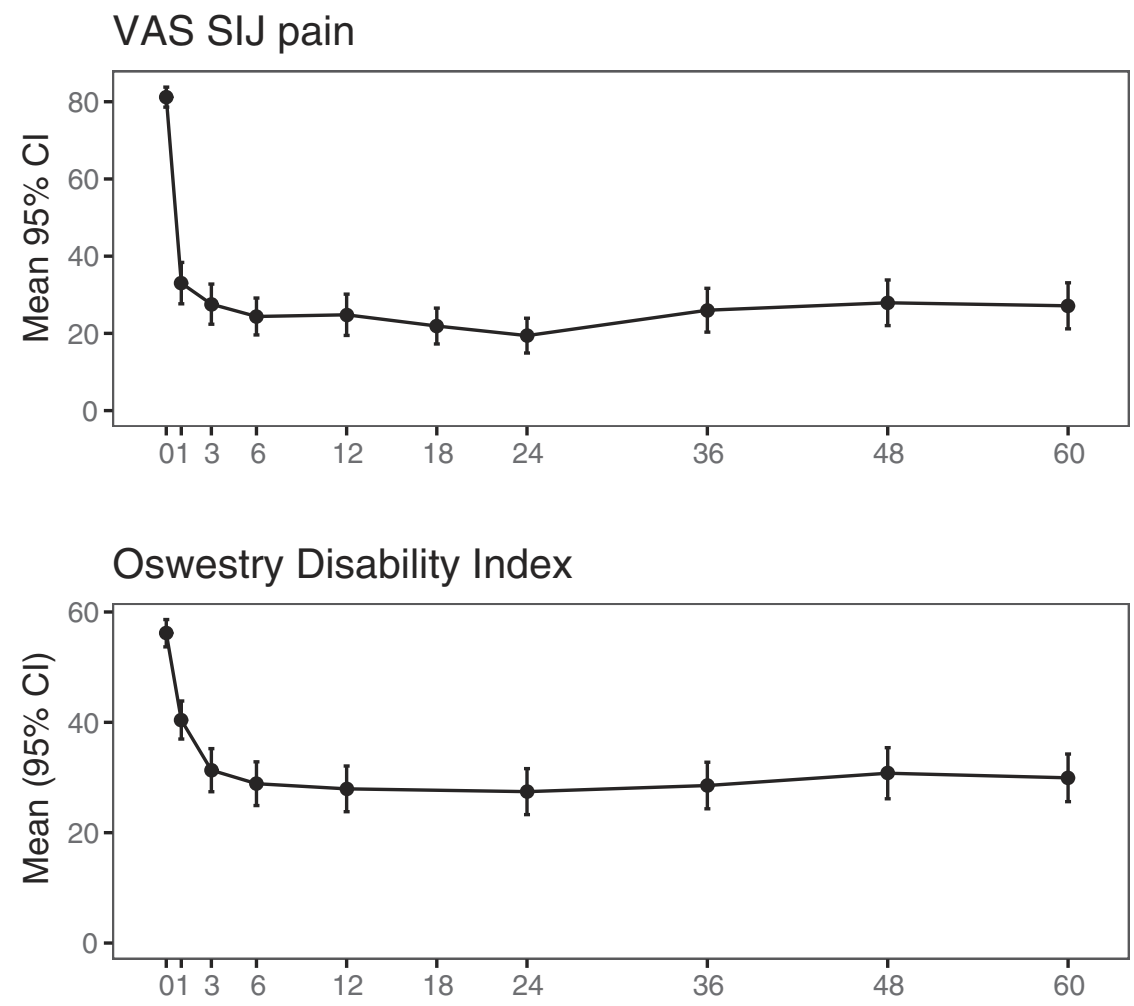

EQ-5D TTO Index

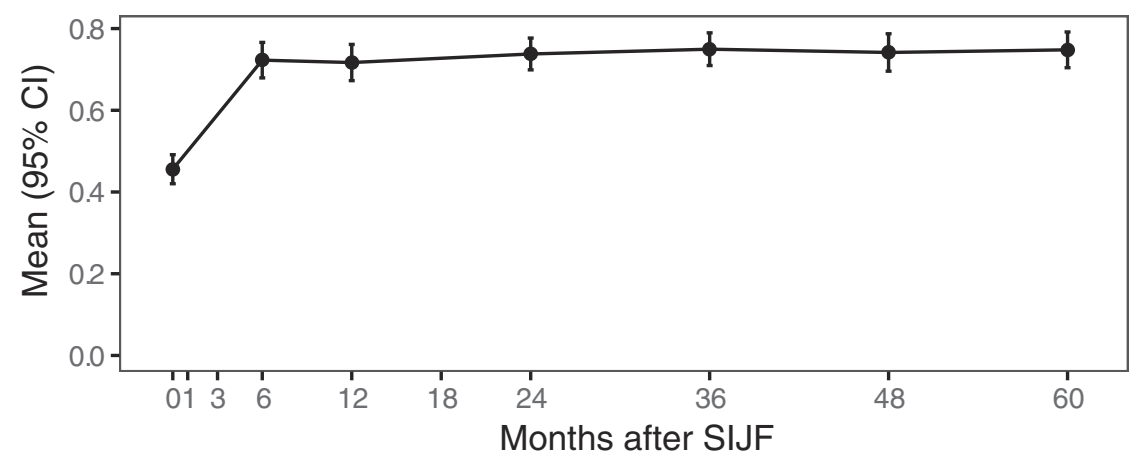

Figure 2 Improvement in SIJ pain (by visual analog scale, top), disability (Oswestry Disability Index, middle) and quality of life (EuroQOL-5D TTO index, bottom) over time.

measure of health state utility, improved from $0.45(0.17)$ at baseline to $0.75(0.22)$ at 5 years, an improvement of $0.29(0.26)$ points $(\mathrm{p}<0.0001)$.

Satisfaction rates with SIJF were high at 6 months and remained high throughout the entire follow-up period (Figure 3 ). The proportion of patients who would definitely undergo the procedure again was high at 24 months (85\%) but decreased somewhat at 5 years $(75 \%)$. The proportion who would not have the procedure again was very low throughout the follow-up period (2-6\%). Satisfaction rates correlated with improvement in SIJ pain and ODI. Opioid use decreased progressively over time (Figure 4).
The proportion of subjects who were working full time decreased perioperatively but returned to preoperative levels by 6 months (Figure 5). The proportion not working due to back pain was $16.5 \%$ at baseline and $15.1 \%$ at 5 years (McNemar $\mathrm{p}=0.6056)$.

Three hundred and twenty-eight adverse events were reported in 95 participating subjects, most of which were unrelated to the pelvis or spine. Forty-eight events in 42 subjects involved the pelvis; these included SIJ pain (16), contralateral SIJ pain (18); buttock pain and thigh numbness/ tingling (1); hip and leg pain radicular hip pain (3), trochanteric bursitis (7), hip gluteus minimus tear (1), pelvic floor 

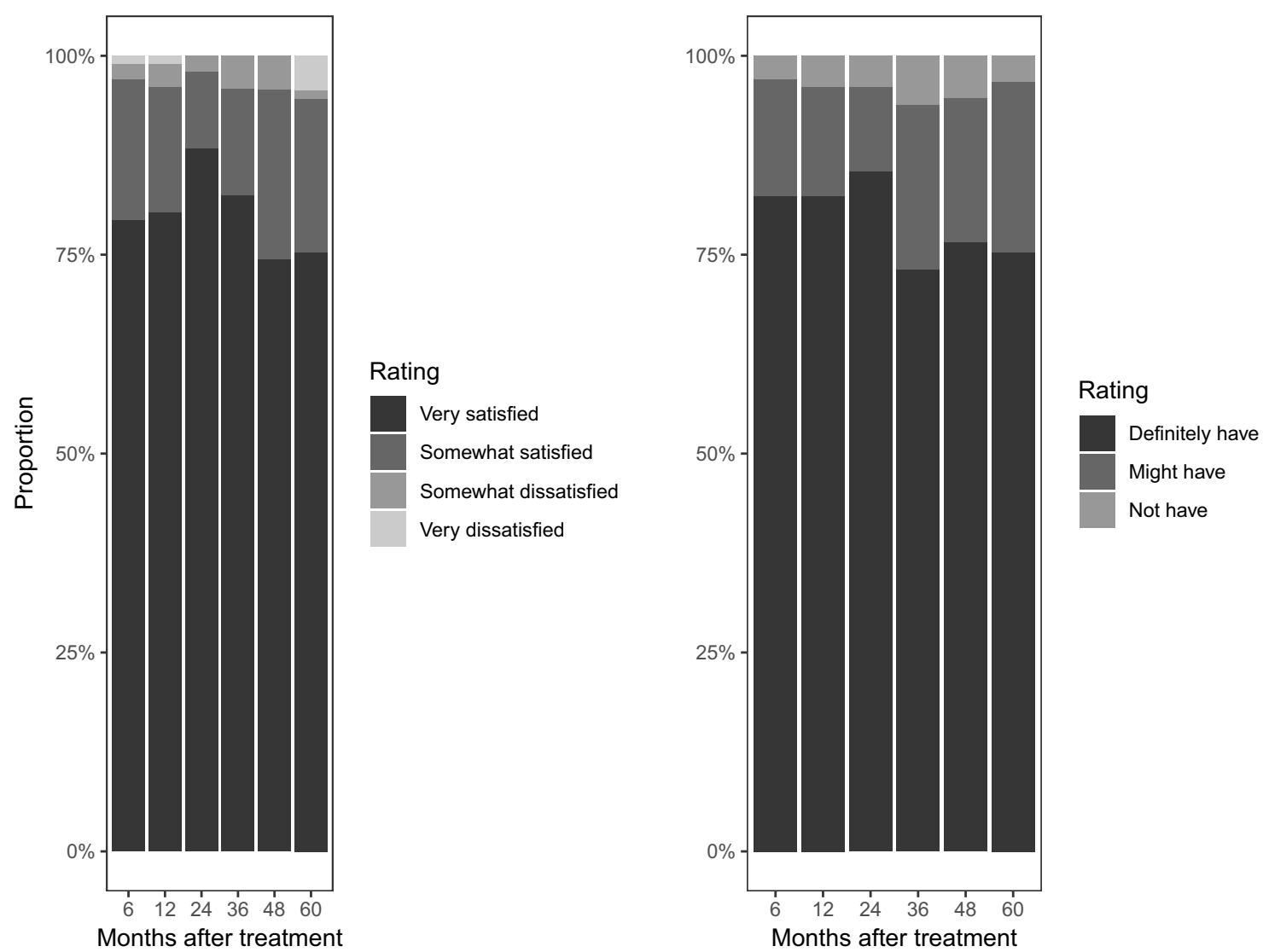

Figure 3 Left: satisfaction levels by study visit. Right: whether the subject would have the procedure again by study visit.

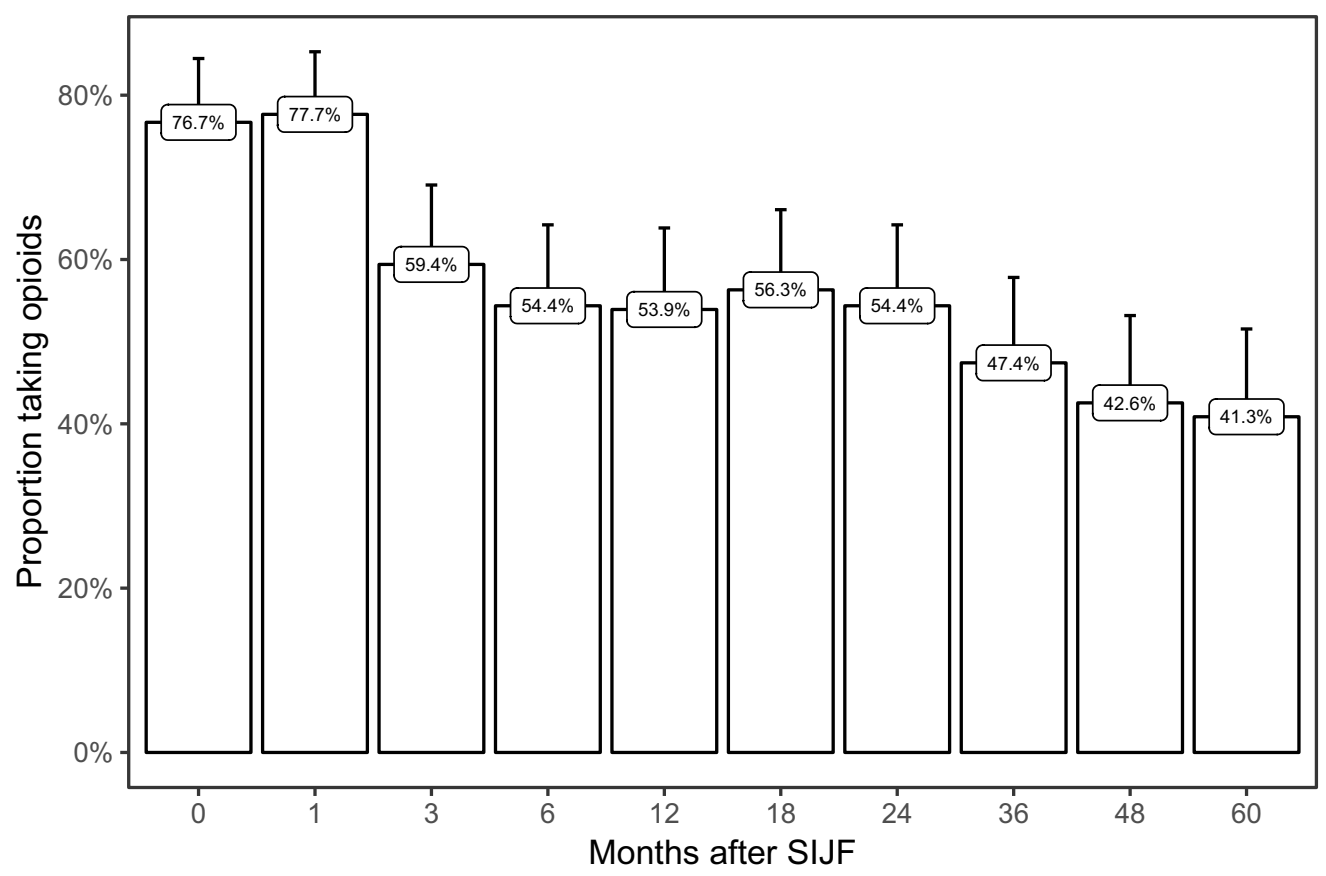

Figure 4 Proportion of subjects taking opioids by study visit. 


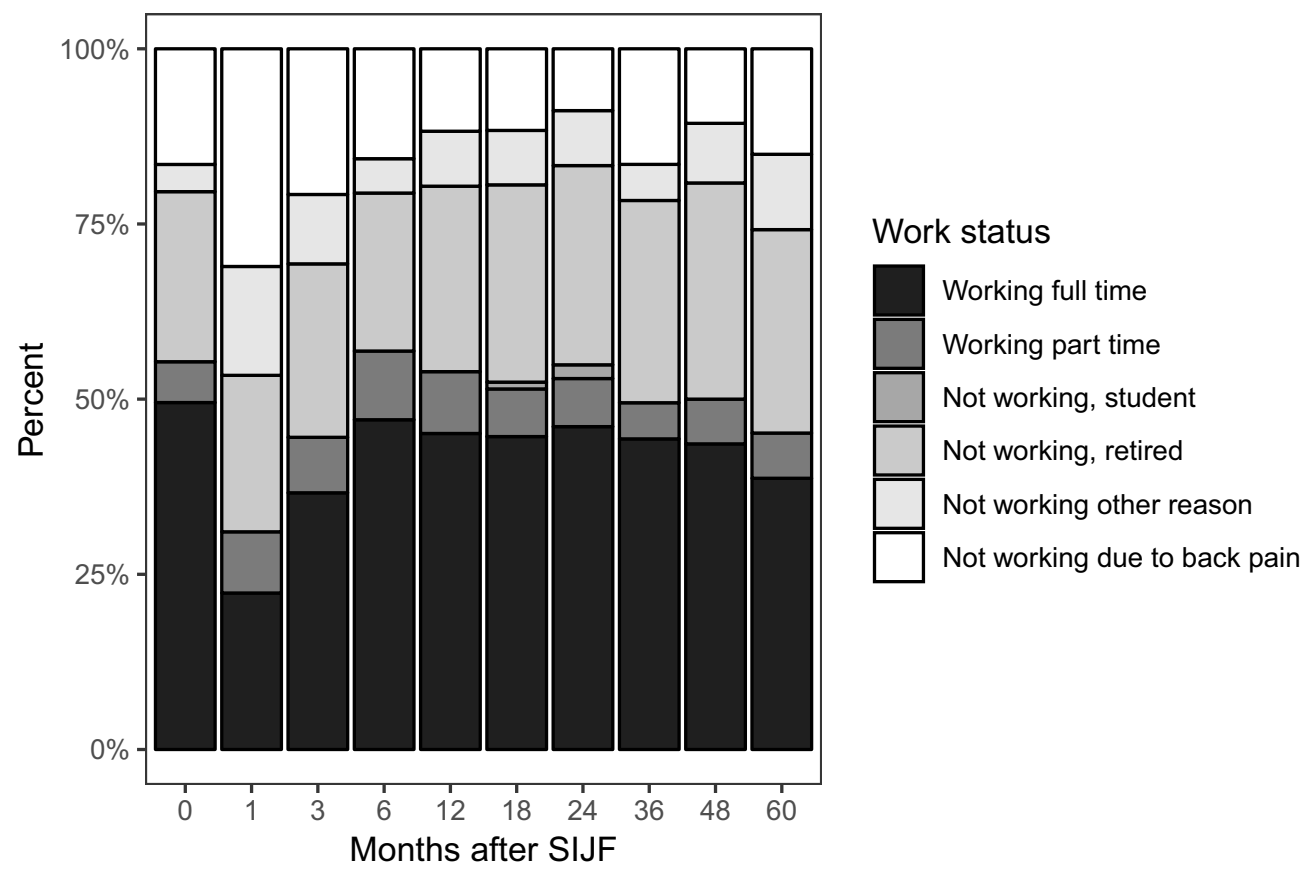

Figure 5 Work status by study visit.

nerve impingement after lumbar fusion unrelated to index SIJ fusion (1) and pelvic organ prolapse (1). Only 1 event intermittent hip and gluteal pain likely to be trochanteric bursitis - was rated as related to the study device. One event -SIJ pain - was deemed related to the study procedure; this subject underwent placement of an additional TTI due to prior with partial resolution of SIJ pain. Of 43 severe adverse events, most were unrelated to the pelvis and none were device-related. One event was classified as being probably procedure-related (the previously described revision due to poor implant placement). Including 1 subject who underwent SIJ revision surgery during the SIFI study, a total of 3 of 103 enrolled subjects in LOIS underwent SIJ revision by 5 years (3\%). Three subjects reported exacerbations of their SI joint pain related to falls. By 5 years, 2 subjects died from conditions unrelated to the SIJ (lung cancer and myocardial infarction).

\section{Radiographic Outcomes}

Five-year CT scans for radiographic analysis were available in $93(90 \%)$ enrolled subjects comprising 121 treated sides. In 67 cases, CTs were available at 12 and 60 months; in 25 cases, studies were available at 24 and 60 months; and in 1 case, a CT was available only at 60 months. Reasons for a CT scan not being available included: loss to follow-up (6); voluntary withdrawal prior to 5 years (2); early termination (2). Sample findings from CT scan analysis are shown in Figures 6 and 7. Detailed results are provided below.

10 subjects underwent interim SIJF between 2 and 5 years; these sides were eliminated from radiographic analysis as their 5-year CT scans do not represent 5 years of residence in the body. All analysis therefore included in 111 sides. Of 111 sides, 109 (98\%) met the primary radiographic endpoint with $>30 \%$ apposition of bone to the ilial and sacral sides of at least 2 implants. In one instance of a single side not meeting the primary endpoint, the subject had undergone explantation of iFuse implants against the recommendations of the investigator. In addition, evaluation of another construct showed the second and third implants inadequately placed into the sacrum, possibly resulting in suboptimal SIJ stabilization that prevented bony apposition in the sacrum. Compared to 1- or 2year scans, bony integration of implants with adequate apposition remained stable at 5 years with no deterioration.

Radiolucencies suggesting failure of implant integration were seen in 6 sides $(5 \%)$; in all cases lucencies were seen only in the sacrum; in 5 of 6 cases, one or more implants associated with radiolucencies were inadequately placed into the sacrum.

Bridging of bone within the SIJ was seen in $45 \%$ of sides at 12 months, $71 \%$ at 24 months and $88 \%$ at 60 months. Of 277 implants analyzed on year 5 scans, bridging bone was present adjacent to the implants in $91 \%$, or both adjacent and distant to implants in 25 cases $(9 \%)$. 


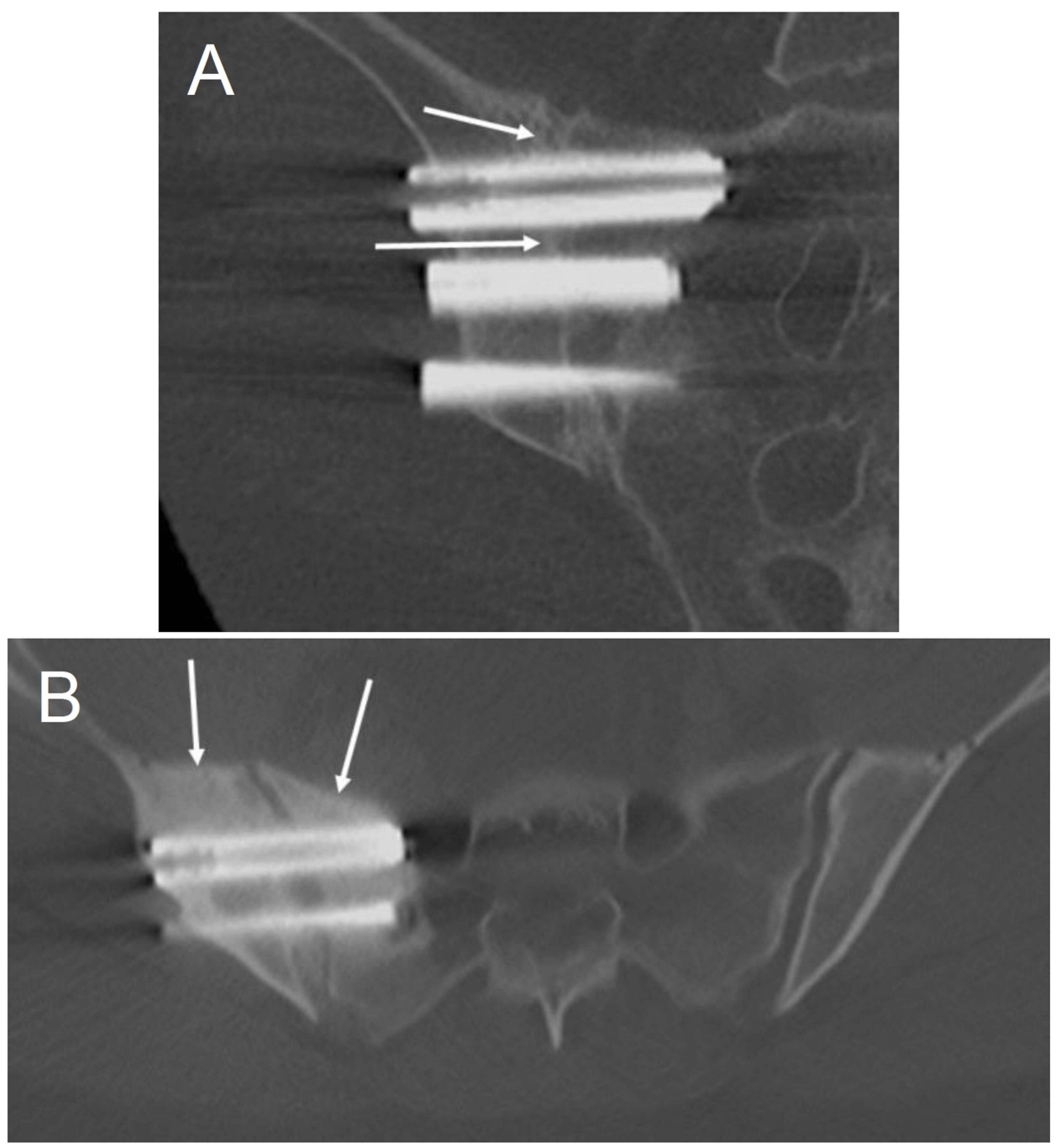

Figure 6 Sample radiographic outcomes. (A) Coronal CT image at 5 years of the right sacroiliac joint showing >30\% bony apposition around all 3 implants and bridging bone adjacent to both the superior and middle implants (white arrows). (B) Axial CT image at 5 years of the right sacroiliac joint demonstrating positive bony remodeling (increased bone density) around the right-sided implants on both the sacral and iliac sides (white arrows).

Seven percent of treated sides showed bridging judged as $>15 \%$ of the SIJ volume.

Positive bone remodeling was seen in $95 \%$ of sides at 60 months. No other adverse bone reactions were seen.

No device migrations or failures were observed and heterotopic ossification was uncommon. Small bone growths abutting the lateral aspect of the implants were frequently noted, occurring in 54/93 (58\%) of sides. Small islands of ossification present in the soft tissue adjacent to the implants but not attached to the implant were seen in 4 cases.

\section{Discussion}

Until recently, surgeons have ignored the SIJ as a source of low back and/or buttock pain, possibly because of surgical treatments perceived as safe and effective were not available. Porous TTI have been commercially available since 2009 and their use is supported by a growing body of evidence. The current study contributes substantially to the evidence base by reporting the long-term (5year) outcomes from prospective multicenter clinical trials in conjunction with an independently adjudicated radiographic analysis. Participants in our study had previously participated in two prospective multicenter trials evaluating SIJF with TTI and returned for 3-, 4- and 5-year follow-up visits. We observed durable long-term improvements in pain, disability and quality of life with sustained high levels of satisfaction such that most patients would elect to undergo the procedure again. Furthermore, opioid use progressively decreased over time following the procedure. 

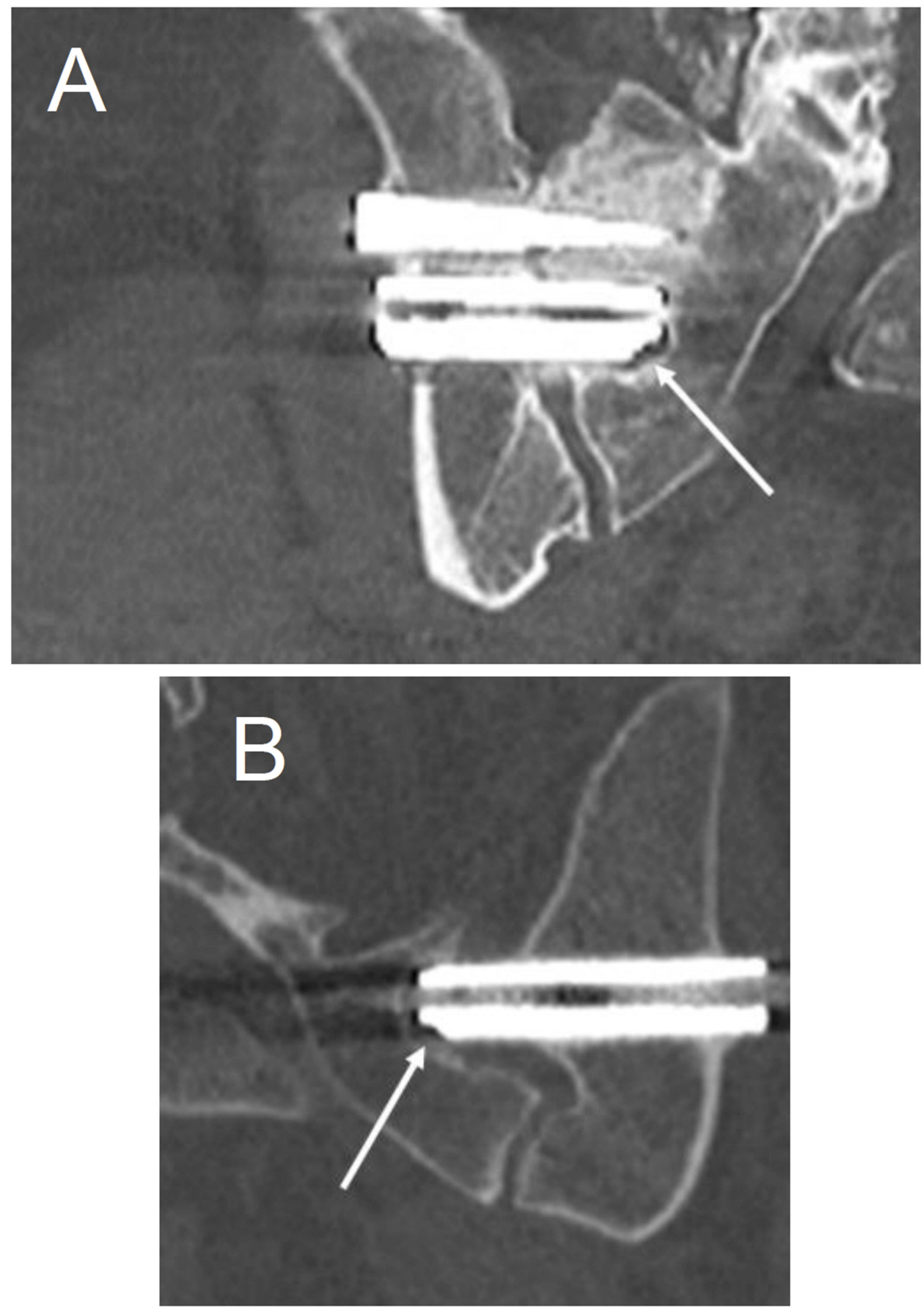

Figure 7 Coronal CT images at 5 years demonstrating radiolucency. (A) A small amount of radiolucency is present around the medial aspect of the middle implant (white arrow) in the right sacroiliac joint. (Note: third implant is out of plane, on a different slice.) Also noted is positive bony remodeling in the sacrum around the superior implant. (B) A second patient with radiolucency (white arrow) around the inferior implant at the left sacroiliac joint. Note the implant is short (i.e., not adequately engaged) in the sacrum.

SIJF with TTI appears to be at least as efficacious as other commonly performed spine surgery procedures (e.g. spinal fusion, total joint replacement). The long-term safety profile of the procedure and device also appears reasonable, with a low rate of subjects undergoing revision surgery in the current study $(3 / 103,3 \%)$. In fact, revision surgery was performed in only one case because initial implant placement was suboptimal.

Our clinical outcome data are also consistent with a European randomized trial, ${ }^{34}$ a long-term case series, ${ }^{35}$ and other reports, ${ }^{19-25}$ which strongly corroborate the long-term safety and effectiveness of SIJF with TTI. 
These findings argue strongly against an apparent bias by many physicians that SIJ-mediated back and/or buttock pain is challenging to diagnose and treat. Indeed, these various studies suggest that SIJ pain can be reliably diagnosed and successfully addressed over the long term through a combination of diagnostic modalities (composed primarily of history, physical examination and response to diagnostic SIJ blocks) and a definitive, anatomically based surgical procedure. The results of surgery are significantly better compared to non-surgical treatments for SIJ dysfunction, none of which have been shown to provide longterm benefits; in general, the evidence supporting commonly performed non-surgical treatments (e.g., intraarticular corticosteroids, physical therapy) is largely scant or even non-existent.

In our study, contralateral SIJ pain was observed in 18 $(17 \%)$ of study participants. Our study cannot discern which of the following reason serves as the primary rationale for this finding: 1) the same degenerative process that involved the index side subsequently affected the contralateral side; 2) the subject had bilateral pain at baseline but only one (the index) side was found to be eligible for surgery within the study; 3 ) increased activity as a result of successful index side surgery exacerbated the contralateral SIJ; or 4) fusion of the index side altered the biomechanical forces across the contralateral SIJ and hastened the development of degeneration, i.e., a crossbody variant on adjacent segment disease. Since SIJF does not appear to increase motion or stress across the contralateral SIJ, ${ }^{36}$ it is unlikely that this procedure would result in adjacent segment degeneration. Similarly, there is little evidence that SIJF increases the risk of hip $^{37}$ or lumbar spine pathology. ${ }^{38}$

An important unique feature of our study is an independent comparative analysis of CT scans performed at 1 or 2 years in the initial studies to images obtained at 5 years in the current study. The CT analysis revealed positive findings including a very high rate of bone apposition to implants in both the sacrum and ilium, a low rate of radiolucencies suggestive of implant loosening, and progressive fusion of the SIJ. Radiolucencies typically occurred around the distal (leading) ends of implants, most commonly when they were not introduced far enough into the sacrum. It is hypothesized that shallow implant placement gives rise to poor fixation and allows for residual joint motion which may prevent bony apposition. In theory, the incidence of implant loosening may be lowered even further by improving the accuracy of implant placement with full engagement into the sacrum. The low revision rate observed in our study is consistent with previous publication of safety analyses which also demonstrated very low cumulative revision rates. ${ }^{39-41}$ The low revision rate also suggests that progressive fusion evident in 5-year CT scans is clinically relevant and establishes the efficacy of this procedure. Furthermore, the radiographic findings from this study are consistent with high fusion rates observed in a smaller retrospective cohort. ${ }^{42}$

The major advantage of our study is prospective longterm follow-up of a relatively large number of subjects from two clinical trials (one a randomized trial) conducted in a variety of clinic settings as well as detailed independent radiographic analysis. It is also important to emphasize that our data derive from procedures performed by surgeons; it is not current practice for these implants to be placed by non-surgeons and their use by other practitioners is not recommended. Moreover, the results presented herein apply to only to TTI placed through a lateral transiliac approach and not to other devices advocated for lateral transiliac SIJF, for which long-term data supporting safety and effectiveness have not been published. The TTI used in our study are not only designed to confer immediate stability by resisting joint nutation (i.e., rotation) but they also have a porous surface specifically designed to promote bone apposition, a finding which was demonstrated on 5-year CT scans. Thus, it is unclear whether the results of our study would be applicable to other devices placed through a lateral transiliac approach and it is highly unlikely that they would be germane to other implant/products inserted posteriorly for which there is a paucity of published clinical data.

The primary limitation of this study is the lack of longterm data from a concurrent control group receiving only non-surgical treatments for SIJ dysfunction. Nevertheless, the majority of subjects in the non-surgical control cohort of the INSITE study experienced inadequate pain relief at 6 months and analogous findings were also observed in the non-surgical control group of a European randomized controlled trial involving the same implant system. ${ }^{34}$ It should be noted that long-term non-surgical care in this patient population is associated with very poor outcomes in terms of worsening pain, increased opioid use, and poor work status. ${ }^{35}$ In contrast to non-surgical care, which provides little benefit to patients with chronic SIJ pain, our collective results suggest that SIJF with TTI gives rise to marked improvements in pain, disability, and quality of life, with high rates of satisfaction and decreased opioid use. In 
addition, the radiographic analysis confirmed high rates of bony apposition to implants and joint fusion.

\section{Conclusions}

Prospective long-term (5-year) follow-up of subjects undergoing SIJF with TTI demonstrate significant improvements in pain, disability and quality of life, excellent patient satisfaction, low risk of complications, and high rates of bony apposition to implants (98\%) and joint fusion $(88 \%)$.

\section{Disclosure}

All authors conduct clinical research as part of prospective trials sponsored by SI-BONE. Peter Whang, Philip Ploska, $S$ Craig Meyer and Clay Frank are paid consultants of SI-BONE. Harry Lockstadt reports non-financial support from SI-BONE, during the conduct of the study and personal fees from SI-BONE, outside the submitted work. Andy Redmond is an investor for Statera Spine, a company involved in spinal imaging. He is also a partner in West End Bay Partners LLC., a start up company dedicated to the treatment of sacroiliac joint pain. Dr. Redmond has a patent pending for sacroiliac joint stabilization and fixation devices and related methods. Application number 16/418,619. Daniel Cher is an employee for SI-BONE, Inc. Travis Hillen was paid for independent radiographic reads as part of this study and a consultant for Medtronic, outside the submitted work. The authors report no other conflicts of interest in this work.

\section{References}

1. Sembrano JN, Polly DW. How often is low back pain not coming from the back? Spine. 2009;34(1):E27-E32. doi:10.1097/BRS.0b013e31818 b8882

2. Bernard TN, Kirkaldy-Willis WH. Recognizing specific characteristics of nonspecific low back pain. Clin Orthop. 1987;217:266-280. doi:10.1097/00003086-198704000-00029

3. Schwarzer AC, Aprill CN, Bogduk N. The sacroiliac joint in chronic low back pain. Spine. 1995;20(1):31-37. doi:10.1097/00007632-19950 1000-00007

4. Maigne JY, Aivaliklis A, Pfefer F. Results of sacroiliac joint double block and value of sacroiliac pain provocation tests in 54 patients with low back pain. Spine. 1996;21(16):1889-1892. doi:10.1097/00007632199608150-00012

5. Irwin RW, Watson T, Minick RP, Ambrosius WT. Age, body mass index, and gender differences in sacroiliac joint pathology. $\mathrm{Am} \mathrm{J}$ Phys Med Rehabil. 2007;86(1):37-44. doi:10.1097/PHM.0b013e31802 b8554

6. Cher D, Polly D, Berven S. Sacroiliac joint pain: burden of disease. Med Devices Evid Res. 2014;7:73-81. doi:10.2147/MDER.S55197

7. Cher DJ, Reckling WC. Quality of life in preoperative patients with sacroiliac joint dysfunction is at least as depressed as in other lumbar spinal conditions. Med Devices Evid Res. 2015;8:395-403. doi:10.21 47/MDER.S92070
8. Luukkainen R, Nissilä M, Asikainen E, et al. Periarticular corticosteroid treatment of the sacroiliac joint in patients with seronegative spondylarthropathy. Clin Exp Rheumatol. 1999;17(1):88-90.

9. Luukkainen RK, Wennerstrand PV, Kautiainen HH, Sanila MT, Asikainen EL. Efficacy of periarticular corticosteroid treatment of the sacroiliac joint in non-spondylarthropathic patients with chronic low back pain in the region of the sacroiliac joint. Clin Exp Rheumatol. 2002;20(1):52-54.

10. Maugars Y, Mathis C, Berthelot JM, Charlier C, Prost A. Assessment of the efficacy of sacroiliac corticosteroid injections in spondylarthropathies: a double-blind study. Br J Rheumatol. 1996;35(8):767770. doi:10.1093/rheumatology/35.8.767

11. Cohen SP, Hurley RW, Buckenmaier CC, Kurihara C, Morlando B, Dragovich A. Randomized placebo-controlled study evaluating lateral branch radiofrequency denervation for sacroiliac joint pain. Anesthesiology. 2008;109(2):279-288. doi:10.1097/ALN.0b013e318 $17 \mathrm{f} 4 \mathrm{c} 7 \mathrm{c}$

12. Patel N, Gross A, Brown L, Gekht G. A randomized, placebo-controlled study to assess the efficacy of lateral branch neurotomy for chronic sacroiliac joint pain. Pain Med. 2012;13(3):383-398. doi:10.1111/j.1526-4637.2012.01328.x

13. Kim WM, Lee HG, Jeong CW, Kim CM, Yoon MH. A randomized controlled trial of intra-articular prolotherapy versus steroid injection for sacroiliac joint pain. J Altern Complement Med N Y N. 2010;16 (12):1285-1290. doi:10.1089/acm.2010.0031

14. Blue Cross Blue Shield Association. Diagnosis and treatment of sacroiliac joint pain - evidence summary. Evidence Street; 2018. Available from: https://app.evidencestreet.com/. Accessed September $13,2019$.

15. Minimally invasive sacroiliac joint fusion surgery for chronic sacroiliac pain | Guidance | NICE. Inteventional procedure guidance (IPG578). National Institute for Health and Care Excellence. Availble from: https://www.nice.org.uk/guidance/IPG578/chapter/1recommendations. Accessed June 11, 2019.

16. Polly DW, Swofford J, Whang PG, et al. Two-year outcomes from a randomized controlled trial of minimally invasive sacroiliac joint fusion vs. non-surgical management for sacroiliac joint dysfunction. Int J Spine Surg. 2016;10:Article 28. doi:10.14444/3028

17. Sturesson B, Kools D, Pflugmacher R, Gasbarrini A, Prestamburgo D, Dengler J. Six-month outcomes from a randomized controlled trial of minimally invasive si joint fusion with triangular titanium implants vs. conservative management. Eur Spine J. 2017;26(3):708-719. doi:10.1007/s00586-016-4599-9.

18. Duhon BS, Bitan F, Lockstadt H, Kovalsky D, Cher D, Hillen T. Triangular titanium implants for minimally invasive sacroiliac joint fusion: 2-year follow-up from a prospective multicenter trial. Int $J$ Spine Surg. 2016;10:Article 13. doi:10.14444/3013

19. Rudolf L. Sacroiliac joint arthrodesis-MIS technique with titanium implants: report of the first 50 patients and outcomes. Open Orthop J. 2012;6(1):495-502. doi:10.2174/1874325001206010495

20. Rudolf L. MIS fusion of the SI Joint: does prior lumbar spinal fusion affect patient outcomes? Open Orthop J. 2013;7:163-168. doi:10.21 74/1874325001307010163

21. Sachs D, Capobianco R. One year successful outcomes for novel sacroiliac joint arthrodesis system. Ann Surg Innov Res. 2012;6(1):13. doi:10.1186/1750-1164-6-13

22. Sachs D, Capobianco R. Minimally invasive sacroiliac joint fusion: one-year outcomes in 40 patients. Adv Orthop. 2013;2013:536128. doi: $10.1155 / 2013 / 536128$

23. Cummings J Jr, Capobianco RA. Minimally invasive sacroiliac joint fusion: one-year outcomes in 18 patients. Ann Surg Innov Res. 2013;7 (1):1-7. doi:10.1186/1750-1164-7-12

24. Schroeder JE, Cunningham ME, Ross T, Boachie-Adjei O. Early results of sacro-iliac joint fixation following long fusion to the sacrum in adult spine deformity. Hosp Spec Surg J. 2013;10(1):3035. doi:10.1007/s11420-013-9374-4 
25. Smith AG, Capobianco R, Cher D, et al. Open versus minimally invasive sacroiliac joint fusion: a multi-center comparison of perioperative measures and clinical outcomes. Ann Surg Innov Res. 2013;7 (1):14. doi:10.1186/1750-1164-7-14

26. Ledonio CGT, Polly DW, Swiontkowski MF. Minimally invasive versus open sacroiliac joint fusion: are they similarly safe and effective? Clin Orthop. 2014;472(6):1831-1838. doi:10.1007/s11999-014-3499-8

27. Ledonio C, Polly D, Swiontkowski MF, Cummings J. Comparative effectiveness of open versus minimally invasive sacroiliac joint fusion. Med Devices Evid Res. 2014;2014(7):187-193. doi:10.2147/ MDER.S60370

28. Dengler J, Duhon B, Whang P, et al. Predictors of outcome in conservative and minimally invasive surgical management of pain originating from the sacroiliac joint: a pooled analysis. Spine. 2017;42(21):1664-1673. Epub 2017 Mar 27. doi:10.1097/BRS.00 00000000002169

29. Fortin JD, Falco FJ. The Fortin finger test: an indicator of sacroiliac pain. Am J Orthop Belle Mead NJ. 1997;26(7):477-480.

30. Fairbank JC, Pynsent PB. The Oswestry disability index. Spine. 2000;25(22):2940-2952; discussion 2952. doi:10.1097/00007632200011150-00017

31. EuroQol Group. EuroQol-a new facility for the measurement of health-related quality of life. Health Policy Amst Neth. 1990;16 (3):199-208. doi:10.1016/0168-8510(90)90421-9

32. Howard JL, Hui AJ, Bourne RB, Holdsworth DW. Computed tomographic analysis of bone support for three acetabular cup designs. Clin Orthop. 2005;434:163-169. doi:10.1097/01.blo.0000151442.60652.ac

33. The Yale Open Data Access (YODA) project. Available from: http:// yoda.yale.edu/. Accessed June 1, 2019

34. Dengler J, Kools D, Pflugmacher R, et al. Randomized trial of sacroiliac joint arthrodesis compared with conservative management for chronic low back pain attributed to the sacroiliac joint. $J$ Bone Joint Surg Am. 2019;101(5):400-411. doi:10.2106/JBJS.18.00022
35. Vanaclocha V, Herrera JM, Sáiz-Sapena N, Rivera-Paz M, VerdúLópez F. Minimally invasive sacroiliac joint fusion, radiofrequency denervation, and conservative management for sacroiliac joint pain: 6-year comparative case series. Neurosurgery. 2018;82(1):48-55. doi:10.1093/neuros/nyx185

36. Lindsey D, Kiapour A, Gundanna M, Yerby SA, Goel A Does sacroiliac joint fusion alter contralateral joint loading? Finite element analysis of a minimally invasive procedure. In: International Society for the Advancement of Spine Surgery; 2016; Las Vegas, NV.

37. Joukar A, Chande R, Carpenter RD, et al. Sacroiliac joint stabilization does not alter contact stresses across the hip joint - A finite element study. In: Annual Meeting of the Orthopaedic Research Society; February 2-5, 2019; paper 0019; Austin, TX.

38. Lindsey DP, Kiapour A, Yerby SA, Goel VK. Sacroiliac joint fusion minimally affects adjacent lumbar segment motion: a finite element study. Int J Spine Surg. 2015;9:64. doi:10.14444/2064

39. Miller L, Reckling WC, Block JE. Analysis of postmarket complaints database for the iFuse SI Joint Fusion System: a minimally invasive treatment for degenerative sacroiliitis and sacroiliac joint disruption. Med Devices Evid Res. 2013;6:77-84. doi:10.2147/MDER.S44690

40. Cher DJ, Reckling WC, Capobianco RA. Implant survivorship analysis after minimally invasive sacroiliac joint fusion using the iFuse implant system. Med Devices Evid Res. 2015;8:485-492. doi:10.21 47/MDER.S94885

41. Cher D, Wroe K, Reckling WC, Yerby S. Postmarket surveillance of 3D-printed implants for sacroiliac joint fusion. Med Devices Auckl NZ. 2018;11:337-343. doi:10.2147/MDER.S180958

42. Rudolf L, Capobianco R. Five-year clinical and radiographic outcomes after minimally invasive sacroiliac joint fusion using triangular implants. Open Orthop J. 2014;8:375-383. doi:10.2174/187432 5001408010375
Medical Devices: Evidence and Research

\section{Publish your work in this journal}

Medical Devices: Evidence and Research is an international, peerreviewed, open access journal that focuses on the evidence, technology, research, and expert opinion supporting the use and application of medical devices in the diagnosis, monitoring, treatment and management of clinical conditions and physiological processes. The identification of novel devices and optimal use of existing devices

\section{Dovepress}

which will lead to improved clinical outcomes and more effective patient management and safety is a key feature of the journal The manuscript management system is completely online and includes a very quick and fair peer-review system. Visit http:// www.dovepress.com/testimonials.php to read real quotes from published authors. 